\title{
A New AR-Based Framework For Wrist Assessment And Rehabilitation
}

\author{
Lu Zeng ${ }^{1}$, Bingjin $\mathrm{Ji}^{2^{*}}$, Xiao $\mathrm{Li}^{{ }^{*}}$ \\ ${ }^{1}$ School of Computer and Information Science( Southwest University), Chongqing, 400700, China \\ ${ }^{2}$ Beibei Traditional Chinese Medical Hospital, Chongqing,400700, China \\ (*Bingjin $\mathrm{Ji}$, *Xiao Li : corresponding authors)
}

Keywords: Augmented Reality ; Wrist Assessment and Rehabilitation; Framework ; Kinesiotherapy and Occupational Therapy

\begin{abstract}
The existing rehabilitation systems based on augmented reality $(A R)$ are lacking of the targeted training of joint and requiring a large number of auxiliary equipment. This paper proposes a novel framework for wrist-rehabilitation assessment and training that integrates AR technology with kinesiotherapy and occupational therapy in rehabilitation medicine, which focuses on coaching patients to wrist radial and ulnar deviation rehabilitation at any time and any place. Particularly, an AR-based water-droplet training game, suggested by clinical doctors in hospital, is developed to improve the flexibility of the wrist movement. The effect of rehabilitation can be achieved by measuring the range of motion (ROM) of the wrist. Finally, the evaluation scheme of this framework is designed in detail.
\end{abstract}

\section{Introduction}

Wrist is the pathway that flexor or extensor tendons of forearm blood vessels and nerves arrive to the hand ${ }^{[1]}$. However, because of bearing a larger load in the support, thrust and other movements, so the wrist is easily damaged. Fortunately, research studies have confirmed that early rehabilitation training is extremely important to wrist function recovery ${ }^{[2]}$. At present, the "one-to-one" rehabilitation model of traditional rehabilitation can not meet the needs of society; Rehabilitation training system based on Virtual Reality (VR) technology such as BioMaster [3] and Upper Limb Rehabilitation Intelligent $\operatorname{Robot}^{[4]}$, the patients tend to feel boredom when facing the virtual world which is completely different from the real world. Augmented Reality technology (AR) is introduced into rehabilitation medicine. It can add virtual object which is generated by computer into accurate place in the real scene and present a new sense of the real effect of the new environment ${ }^{[5]}$. The system, which combines AR technology with the functional training of the wrist, can construct a virtual-reality fusion training environment to make patients keep in touch with the real world. Obviously, it is helpful to improve the rehabilitation better.

This paper presents a novel framework that provides an entertaining and natural environment for wrist-rehabilitation assessment and training. The rest of the paper is organized as follows: in session 2 related works are highlighted while session 3 presents the overall architecture of the system and general process of wrist assessment and rehabilitation in details. Conclusions and future work is provided in section 4.

\section{Related Work}

At present, foreign researches are started earlier and developed rapidly while domestic researches are still in the early stage of laboratory research at present. The following Table 1 enumerates some of present AR-based rehabilitation systems ${ }^{[6,7,8,9,10,11,12]}$, which can be carried out wrist training, with a comparative analysis of these systems' three aspects that include the components, training process, evaluation methods and features of system.

These systems can provide a favorable training environment for patients with high interest and deep immersion. But as shown in Table 1, there also are the following disadvantages: 1. these systems constitute cumbersome, resulting in the patient's comfort is not high; 2. Most of the systems are lacking of professional rehabilitation, which is according to the mechanism of sports mechanics and recovery mechanism of the wrist .What's more, all the current $A R$ developments are concentrated only on game design principles, user convenient and just to train for upper limb movements but do not consider for any biofeedback ${ }^{[13]} ; 3$. Most of the rehabilitation evaluation methods are based on the score of games to judge the rehabilitation condition, lacking of specific quantitative indicators and medical evaluation basis.

Different from the existing systems, this paper proposes a new architecture of wrist rehabilitation system that combines AR with kinesiotherapy and occupational therapy in rehabilitation medicine. 


\begin{tabular}{|c|c|c|c|c|}
\hline Project & Components & Training process & $\begin{array}{c}\text { Evaluation } \\
\text { methods }\end{array}$ & System Features \\
\hline $\begin{array}{l}\text { A multi-sensor } \\
\text { multi-rate algorithm for } \\
\text { motor rehabilitation } \\
\text { with Augmented Reality } \\
\text { devices (2016) }\end{array}$ & $\begin{array}{l}\text { HMD, } \\
\text { Web-Camera, } \\
\text { MPU6050 (IMU) }\end{array}$ & $\begin{array}{l}\text { Through the head mounted } \\
\text { display (HMD), in the right } \\
\text { way to open a real plastic } \\
\text { bottle with the guidance of } \\
\text { virtual 3D hands. }\end{array}$ & $\begin{array}{l}\text { Hand-track error } \\
\text { and virtual object } \\
\text { alignment error } \\
\text { in nominal } \\
\text { condition and } \\
\text { critical condition }\end{array}$ & $\begin{array}{l}\text { Multi-sensor and } \\
\text { multi-rate algorithm } \\
\text { can make a reliable } \\
\text { alignment between } \\
\text { real and virtual objects } \\
\text { in real-time }\end{array}$ \\
\hline $\begin{array}{l}\text { Development of a } \\
\text { haptic interface for } \\
\text { motor rehabilitation } \\
\text { therapy using } \\
\text { augmented reality } \\
\text { (2015) }\end{array}$ & $\begin{array}{l}\text { PC, } \\
\text { HMD, } \\
\text { Camera, } \\
\text { Markers, } \\
\text { Haptic device }\end{array}$ & $\begin{array}{l}\text { The patient wears a HMD } \\
\text { to see the rendering of the } \\
\text { virtual ball and completes } \\
\text { the training by touching the } \\
\text { haptic device to hit the } \\
\text { virtual ball. }\end{array}$ & $\begin{array}{l}\text { The number of } \\
\text { repetitions } \\
\text { performed, the } \\
\text { total runtime and } \\
\text { the norm of } \\
\text { tracking error }\end{array}$ & $\begin{array}{l}\text { Allows different types } \\
\text { of visually and tactilely } \\
\text { stimulating exercises }\end{array}$ \\
\hline $\begin{array}{l}\text { Perception of Health } \\
\text { Professional about } \\
\text { Clinical Utility of an } \\
\text { Augmented Reality } \\
\text { Musical System to } \\
\text { Motor and Cognitive } \\
\text { Rehabilitation (2014) }\end{array}$ & $\begin{array}{l}\text { PC, } \\
\text { Camera, } \\
\text { Markers, } \\
\text { Audio }\end{array}$ & $\begin{array}{l}\text { Training through the } \\
\text { rotation and translation } \\
\text { note markers with hand, } \\
\text { the system gives the sound } \\
\text { feedback. }\end{array}$ & $\begin{array}{l}\text { The time required } \\
\text { to complete } \\
\text { specific tasks }\end{array}$ & $\begin{array}{l}\text { The combination of } \\
\text { visual and hearing, } \\
\text { so it can use the } \\
\text { markers to bring } \\
\text { auditory feedback }\end{array}$ \\
\hline $\begin{array}{l}\text { AR Based Upper Limb } \\
\text { Rehabilitation System } \\
\text { (2012) }\end{array}$ & $\begin{array}{l}\text { PC, } \\
\text { Camera, } \\
\text { Color Markers, } \\
\text { Electromyogram } \\
\text { (EMG) }\end{array}$ & $\begin{array}{l}\text { Training through the } \\
\text { balloon collection, feeding } \\
\text { animals and other } 4 \text { games } \\
\text { rehabilitation.For example, } \\
\text { the balloon collection } \\
\text { game: collect the balloon } \\
\text { which randomly generated } \\
\text { from top of the display } \\
\text { screen and place into the } \\
\text { collection box. }\end{array}$ & $\begin{array}{l}\text { Real time } \\
\text { feedback of EMG } \\
\text { signals }\end{array}$ & $\begin{array}{l}\text { A subtle blend of } \\
\text { biofeedback system } \\
\text { with AR and it can } \\
\text { detect the level of } \\
\text { muscle activation of } \\
\text { trainees }\end{array}$ \\
\hline $\begin{array}{l}\text { Out of reach?a novel ar } \\
\text { inerface approach for } \\
\text { motor rehabilitation } \\
\text { (2011) }\end{array}$ & $\begin{array}{l}\text { PC, } \\
\text { Wide-Angle } \\
\text { Webcam, } \\
\text { Modified Fiber- } \\
\text { Board Boxes }\end{array}$ & $\begin{array}{l}\text { The patient put their } \\
\text { hands in the fiber-board } \\
\text { boxes and then move the } \\
\text { virtual tiles which is } \\
\text { displayed by screen to } \\
\text { complete the training. }\end{array}$ & $\begin{array}{l}\text { IBM's usability } \\
\text { satisfaction } \\
\text { questionnaire } \\
\text { and 7-point } \\
\text { Likert-scales to } \\
\text { assess the } \\
\text { usability }\end{array}$ & $\begin{array}{l}\text { The use of mirror-box } \\
\text { therapy can } \\
\text { eliminate the tension } \\
\text { and can completely } \\
\text { immerse in the } \\
\text { training environment }\end{array}$ \\
\hline $\begin{array}{l}\text { Hand rehabilitation } \\
\text { training system based } \\
\text { on Augmented Reality } \\
\text { (2015) }\end{array}$ & $\begin{array}{l}\text { PC, } \\
\text { Camera, } \\
\text { Markers }\end{array}$ & $\begin{array}{l}\text { The system includes three } \\
\text { kinds of training: trajectory } \\
\text { training, cup training and } \\
\text { table tennis training. For } \\
\text { example,trajectory training: } \\
\text { the user makes the virtual } \\
\text { ball along the virtual } \\
\text { trajectory with holding a } \\
\text { small box attached to the } \\
\text { marker. }\end{array}$ & $\begin{array}{l}\text { Comparison } \\
\text { the time to fulfill } \\
\text { tasks and the } \\
\text { score obtained } \\
\text { within the fixed } \\
\text { time }\end{array}$ & $\begin{array}{l}\text { AR system renders } \\
\text { the real scene better } \\
\text { and the game task is } \\
\text { more abundant }\end{array}$ \\
\hline $\begin{array}{l}\text { Upper limb } \\
\text { rehabilitation system } \\
\text { using augmented } \\
\text { reality technology } \\
\text { (2013) }\end{array}$ & $\begin{array}{l}\text { PC, } \\
\text { Camera, } \\
\text { Markers }\end{array}$ & $\begin{array}{l}\text { According to the system } \\
\text { prompts, the patient } \\
\text { move the upper limbs to } \\
\text { complete the task which } \\
\text { is same with gophers game. }\end{array}$ & $\begin{array}{l}\text { Comparison } \\
\text { the score } \\
\text { obtained within } \\
\text { the same degree }\end{array}$ & $\begin{array}{lr}\text { Two types of } \\
\text { interaction: } \\
\text { interaction } \\
\text { gesture interaction }\end{array}$ \\
\hline
\end{tabular}

Table 1 The comparisons of the existing AR-based wrist rehabilitation systems.

\section{Framework Design}

\subsection{Rationale and Principle}

In rehabilitation training, kinesiotherapy is the most commonly used method, which using equipment or the patients' own strength, through some movement, to make the patient obtain systemic or local motor function and sensory function recovery; Occupational therapy refers to the process of evaluating, treating, and training patients who have a physical disability or developmental dysfunction and lose the ability to work independently in some degrees, with a purposeful, selected activity ${ }^{[14]}$. 
The combination of kinesiotherapy and occupational therapy combined with AR technology can provide a highly professional and comfortable wrist rehabilitation program for patients: (1) In the early stage of rehabilitation, through the kinesiotherapy, it can be a good way to avoid the secondary injury by wrist radial and ulnar deviation rehabilitation in small angle; (2) in the late stage, through the occupational therapy, it can enhance the flexibility of the wrist joint and improve the coordination between the bones by completing the receiving water droplets game; (3) AR technology can interact the real world with the virtual world in real time by rendering the virtual scene on the real training joint and provide a strong interest, high immersion training environment for many repetitive training. Obviously, it is more effective than the traditional kinesiotherapy and occupational therapy, which is the way by using wrist function trainer and thumbing screws, etc.

\subsection{System Architecture}

AR-based wrist rehabilitation system can realize the sensor data input, multi -screen (PC, TV, Projector, Android machine) display output function. The conceptual architecture overview is shown in Figure 1.

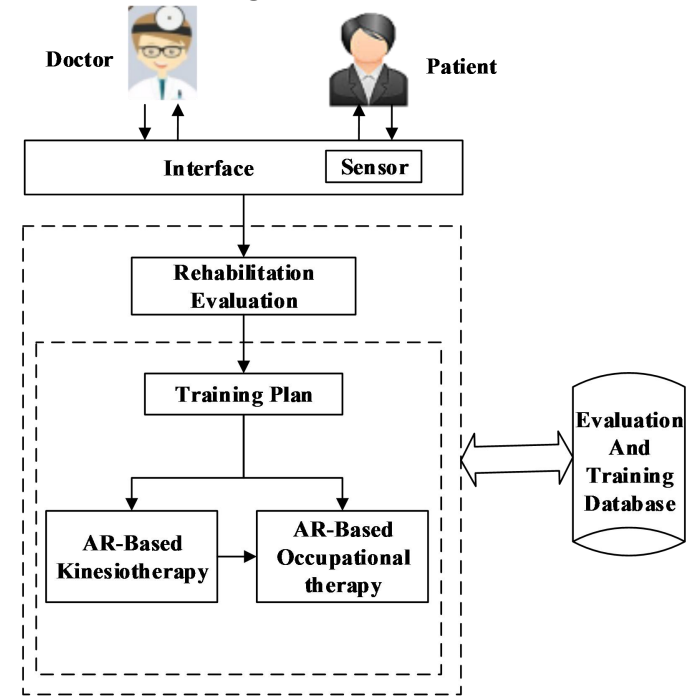

Figure 1: The conceptual architecture overview of AR-based wrist rehabilitation

As shown in Figure 1, the system mainly includes: doctor and patient interface module, rehabilitation evaluation module, rehabilitation training module and data storage module. Among them, rehabilitation training module, which mainly includes two small modules: AR-based kinesiotherapy rehabilitation and AR-based occupational therapy rehabilitation, is the core module of the whole system. The data storage module mainly stores the patient's periodic evaluation records and real-time training records in the evaluation and training database.

\subsection{Evaluation and Training Process}

Before rehabilitation, the patient must undergo a rehabilitation assessment. According to the patient's assessment record, the doctor make the corresponding training plan, including the target angle of kinesiotherapy rehabilitation, the water drop game level of occupational therapy rehabilitation, training time and so on. In the process of rehabilitation, firstly, the patient should log on to their account and see the doctor's training plan. Secondly, wear and proofread the sensor, then select AR-based kinesiotherapy rehabilitation and AR-based occupational therapy rehabilitation for training. Timely training feedback can provide a good incentive to the patient's active training, so after the training, the system will show the patient's comprehensive situation of the training.

\subsubsection{The Work Flow of AR-Based Kinesiotherapy Rehabilitation}

AR-based kinesiotherapy rehabilitation mainly through the virtual 3D wrist rendered by the systems to guide and regulate patients' training actions of wrist radial and ulnar deviation. The specific working process is shown in Figure 2.

Figure 2 The swimlane flowchart of AR-based kinesiotherapy rehabilitation

The patient' real wrist interacts in real time with the system's rendered virtual 3D wrist as depicted in Fig. 2. The system adjusts 3D coordinate information of virtual wrist and redraws other virtual scene information according to the location of the real wrist .So that the real wrist and virtual wrist are always in the same plane anytime. Therefore, patient training is more digestible because of the clearer goal.

\subsubsection{The Work Flow of AR-Based Occupational Therapy Rehabilitation}

AR-based occupational therapy Rehabilitation is mainly the design of water droplets game. The game flow is shown in Figure 3. 


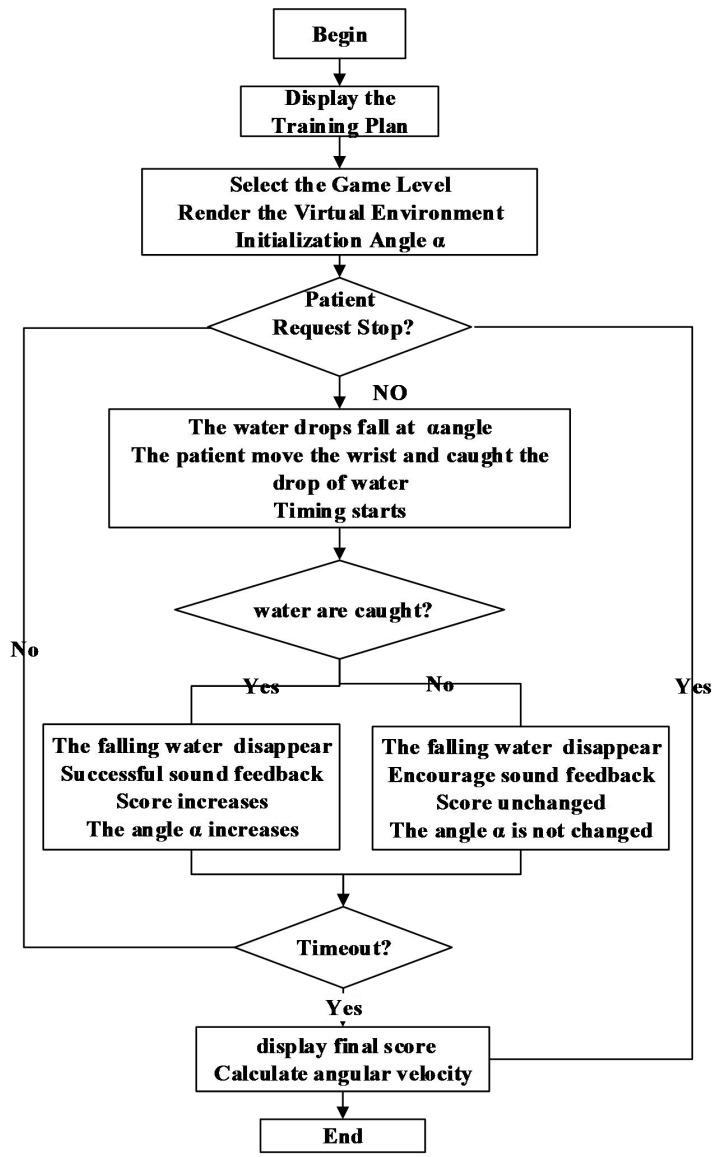

Figure 3: The flow chart of AR-based occupational therapy rehabilitation(water - droplet training game)

Before the game starts, the patients are asked to select a level of difficulty. The game level is designed according to velocity $\beta$ and density $\theta$ of water droplets falling. At the same level, water drops at different angle $\alpha$ (the angle that the central axis that the connection line of water droplets to the starting point of the central axis).

\subsection{Evaluation Scheme}

Measuring the range of motion (ROM) is an important content in rehabilitation assessment. This study will be performed using patients with wrist injury to compare wrist ROM measurement in every stage. Specific details of this evaluation are as follows:

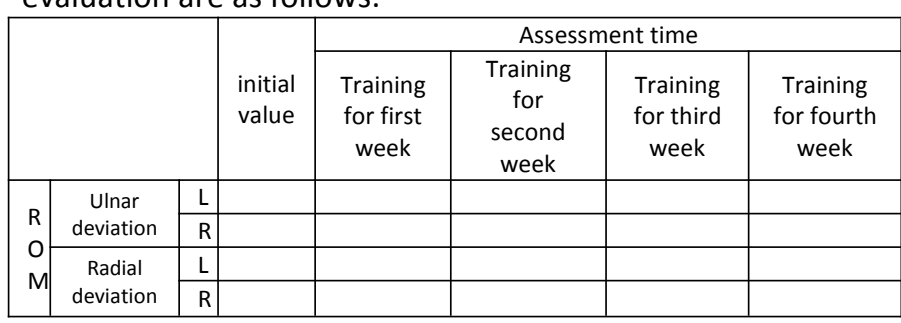

Table 2 : The table of ROM evaluation

The patient is using the application, that this framework is applying to the Android platform and the rehabilitation data is collected by the sensor, for wrist rehabilitation. The maximum curvature of each wrist motion is tracked by a periodic record such as one week. Then, the relevant information will be filled in Table 2 to analyze the rehabilitation of patients.

\section{Conclusions and Future Work}

This paper proposes a novel framework for wristrehabilitation assessment and training that integrates $A R$ technology with kinesiotherapy and occupational therapy in rehabilitation medicine. On the one hand, it is designed according to the special anatomical structure and physiological mechanics of the wrist and easy to use; On the other hand, it can offer real-time feedback of the wrist recovery by using sensors and ROM evaluation method. In the near future, more realistic training scenes will be rendered and more interesting games will be designed.

\section{References}

[1] (In Chinese) Shaoxiang Zhang, Yafang Zhang. Topographic Anatomy (3rd Edition) [M]. Beijing: People's Health Publishing House, 2015.

[2] (In Chinese) Lin Wang. The Causes of Wrist Injury of College Athletic Aerobics Athletes and Rehabilitation [J]. Journal of Nanjing Institute of Physical Education (Natural Science), 2006, 5(3):8-12.

[3] (In Chinese)Todd Ellenbecker, Mark De Carlo, Carl DeRosa. Anli Wang translation. Effectiveness training of exercise rehabilitation [M]. Beijing: Beijing Sport University Press, 2011.

[4] (In Chinese) Yang Xiao, Xiulin Xu. Design of Rehabilitation Evaluation Training System for Hand Function Based on Virtual Reality Technology [J]. Chinese Journal of Rehabilitation Theory and Practice, 2016, 22 (3): 341-344.

[5] (In Chinese) Yongtian Wang, Jing Chen, Deiwen Cheng. Augmented Reality: An Emerging Technologies Gudie to AR [M]. Beijing: Science Press, 2015.

[6] F. D' Ippolito and M. Massaro. A multi-sensor multi-rate algorithm for motor rehabilitation with Augmented Reality devices [C]. 2016 6th IEEE International Conference on Biomedical Robotics and Biomechatronics (BioRob), Singapore, 2016: 759-765.

[7] Vidriosserrano C, Bonilla I, Viguerasgomez F, et al. Development of a haptic interface for motor rehabilitation therapy using augmented reality [C]. Engineering in Medicine \& Biology Society. Conf Proc IEEE Eng Med Biol Soc, 2015:1156-1159.

[8] Dionisio Correa A G, Aparecida D A G, Karaguilla Ficheman, et al. Perception of Health Professional about Clinical Utility of an Augmented Reality Musical System to Motor and Cognitive Rehabilitation [C]. Virtual and Augmented Reality. IEEE, 2014:71-79. 
[9] Aung YM, Adel AJ.AR Based Upper Limb Rehabilitation System [C]. ROma, Intaly : Proceedings of the 4th IEEE RAS\&EMBS International Conference on Biomedical Robotics and Blomenchatronics, 2012:213-218.

[10] Regenbrecht H, McGregor G, Ott C. Out of reach? a novel ar interface approach for motor rehabilitation[C]. Swutzerkangd: Proceedings of the 10th IEEE International Symposium on Mixed and Augmented Reality 2011:219-228.

[11] (In Chinese) Dong Hui Xie. Hand rehabilitation training system based on Augmented Reality [D]. Jiangsu:
Nanjing University of Information Science and Technology, 2016.

[12](In Chinese) Kun Wang. Upper limb rehabilitation system using augmented reality technology [D]. Jiangsu: Southeast University, 2013.

[13] H.Huang, S.Wolf, and J.He, Recent developments in biofeedback for neuromotor rehabilitation, Journal of Neuro Engineering and Rehabilitation,vol.3,p.11,2006.

[14] (In Chinese) Hong Dai. Rehabilitation Medicine (2nd Edition) [M]. Beijing: Peking University Medical Press, 2009.

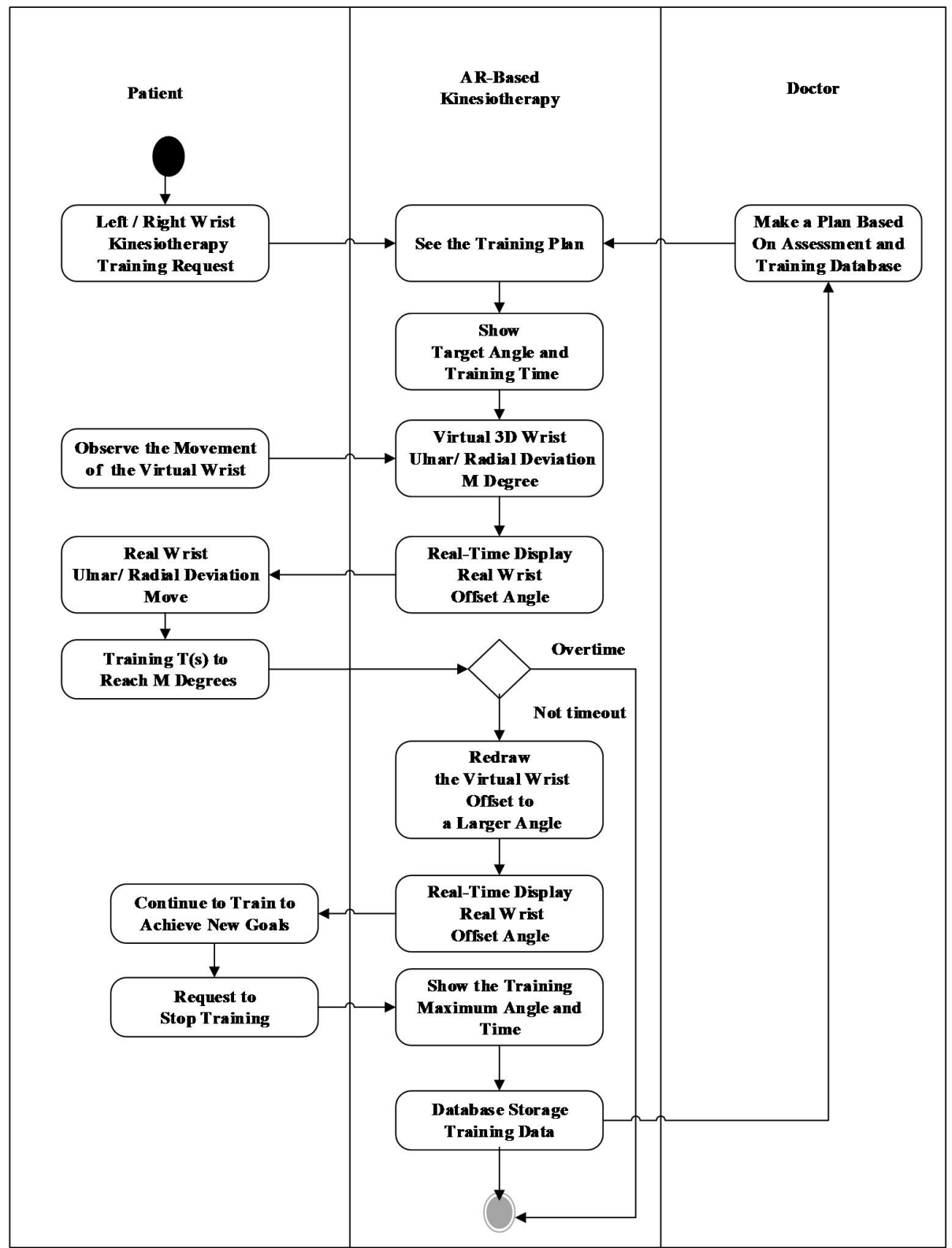

Fig. 2 The swimlane flowchart of AR-based kinesiotherapy rehabilitation 